ST-T wave changes would be difficult to explain without specific myocardial involvement; probably, therefore, these were manifestations of Q-fever myocarditis.

1 Sheridan, P., et al., British Medical fournal, 1974, 2, 155.

Worcester Royal Infirmary, Ronkswood Branch, Worcester WR5 1HN D. BARRACLOUGH, M.B., M.R.A.C.P., Senior House Officer (Present address: M.R.C. Rheumatism Unit, Canadian Red Cross Hospital, Taplow, Maidenhead, Berks)

A. J. POPERT, M.D., F.R.C.P., Consultant Physician

\section{Ultrasound in Management of Clinically Diagnosed Threatened Abortion}

Altogether 237 patients with a clinical diagnosis of threatened abortion were examined ultrasonically to determine whether ultrasound was an accurate aid to clinical diagnosis which could shorten the stay in hospital and reduce the number of uterine evacuations.

\section{Patients, Methods, and Results}

Before their 15th week of pregnancy 237 patients with a clinical diagnosis of threatened abortion were scanned ultrasonically with a Nuclear Enterprises Diasonograph NE4102. Donald's "full bladder technique" was used. Threatened abortion was diagnosed if fetal heart movement was identified." When this was not shown or if the features detailed by Donald $e t$ al. ${ }^{3}$ were present missed abortion was diagnosed. If echoes were seen in the line of the endometrial cavity incomplete abortion was diagnosed. When such echoes were absent or when the cavity showed as a straight line complete echoes were absent or 4 Subsequent management was based entirely the patient's clinical progress, and, apart from one hydatidiform mole, the the patient's clinical progress, and
ultrasonic findings were ignored.

Ultrasound confirmed the clinical diagnosis of threatened abortion in 82 patients $(34.6 \%)$, five of whom subsequently aborted. The remainder continued with normal pregnancies. Missed abortion was diagnosed in 69 patients $(29.1 \%)$ and later became clinically obvious in 67 , three of whom aborted completely and did not undergo surgery. The uterus was evacuated under general anaesthesia in 64 patients, in nine as an emergency procedure. The ultrasonic diagnosis was incorrect in two patients who later delivered healthy infants. Forty patients $(16.9 \%)$ were diagnosed as having incomplete abortion, and evacuation was performed when the pregnancy test result became negative. The ultrasonic findings were confirmed in 37 patients. No curettings were obtained in two cases, and in the third proliferative endometrium was obtained 16 days after the ultrasonic report. Complete abortion was diagnosed in 45 patients (19\%); 16 were discharged from hospital without operation and none had abnormal bleeding subsequently. The remaining 29 were curetted but tissue was obtained from only one. Hydatidiform mole was diagnosed in one patient.

\section{Discussion}

These results illustrate ultrasound's accuracy in diagnosing bleeding in early pregnancy. Misleading results were obtained in only six $(2.5 \%)$ out of 237 patients. Had these findings been acted on the length of hospital stay for many patients could have been reduced (see table). The 28 patients reported as having complete abortions who were subsequently curetted would have avoided an unnecessary operation. The 67 who were correctly diagnosed as having missed abortion would have had evacuation performed as a planned procedure; while waiting for the clinical diagnosis to become obvious nine of them (13.4\%) bled excessively and required emergency

Average Length of Stay in Hospital in 152 Patients with Doomed Pregnancies and Average Time from Ultrasonic Diagnosis to Evacuation

\begin{tabular}{c|c|c|c}
\hline Type of abortion: & Missed & Incomplete & Complete \\
\hline Average stay in hospital (days).. & 8.3 & 7.4 & 4.6 \\
Average time from ultrasonic & $7 \cdot 2$ & 3.2 & 2.2 \\
diagnosis to evacuation (days) & $7 \cdot 2$ & \\
\hline
\end{tabular}

surgery. Of the six misdiagnoses three involved describing small quantities of retained products which were not present at curettage, though one of these could be explained by the 16-day interval between the scan and uterine evacuation. In another patient the scan missed a small quantity of decidua. The most serious errors were the diagnoses of missed abortion in two patients who proceeded with normal pregnancies. One was made in the sixth early pregnancy to be scanned and was almost certainly due to the inexperience of the observer. In the other the scan was unsatisfactory because of an insufficiently distended bladder.

Thus, though ultrasound may be a valuable aid in the diagnosis of bleeding in early pregnancy and may save the patient a long stay in hospital and unnecessary surgery fetal death should never be diagnosed without the confirmation of a second scan and without having made certain that the bladder is adequately filled.

The initial finance for the Diasonograph donated by the Press Stage Children's Charity is gratefully acknowledged.

1 Donald, I., British Medical fournal, 1963, 2, 1154

${ }^{2}$ Robinson, H. P., British Medical fournal, 1972, 4, 446

3 Donald, I., Morley, P., and Barnett, E., Fournal of Obstetrics and Gynaecology of the British Commonwealth, 1972, 79, 304.

4 Campbell, S., British fournal of Hospital Medicine, 1972, 8, 541.

Coombe Lying-in Hospital, Dublin 8

JOHN E. DRUMM, M.B., M.R.C.o.G., Assistant Master

J. CLINCH, M.D., M.R.C.O.G., Master

\section{Running and Primary Osteoarthritis of the Hip}

We studied the hip joints of 74 former runners to find the significance of physical strain in the development of osteoarthritis.

\section{Methods and Results}

Each subject had won several Finnish championships; almost all had made a Finnish record time, and many had achieved a world record. The radiographic examinations were performed between 1963 and 1974. In 1973 questionnaire was sent to all subjects still alive and 60 answered. At examination the average age was 55 (range $31-81$ ). The athletes had started training at 15 (range 12-25), and had participated in running competitions for 21 years (range 8-50). Hip roentgenograms of 115 male patients from the roentgen files of Oulu University Central Hospital were used as controls. roentgen files of oulu had come to hospital because of a hip complaint; the radiograms had been taken for another purpose. The age distribution in this radiograms had been taken for another purpose. The age distribution
group was similar to that of the runners (mean 56, range 40-75).

Results of Roentgenographic Examination of the Hip foints in Top Runners and Control Group

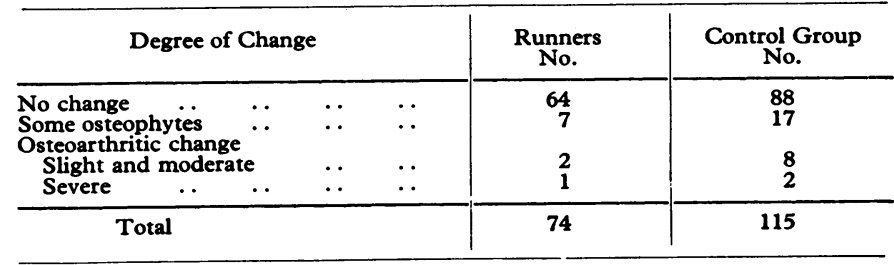

Three athletes had true osteoarthritis. The most difficult to evaluate was a gold medallist who had started his sporting career as late as 23 and finished gold medallist who had started his sporting career as late as 23 and finished after eight years; his hip pains had not started until he was 50 . The 81-year-
old runner who suffered from moderate osteoarthritis had not given up athletics because of his hip. The third athlete (a marathon runner) suffering from osteoarthritis was 75 and had a slight unilateral change in the hip Signs indicating epiphyseolysis could not be found in the roentgenogram of any of the athletes. Osteochondritis dissecans was not found either, an other findings (such as loose bodies and calcium deposits) were unusual.

None of the subjects with a normal finding or a finding with some osteophytes in the radiological examination had hip pains at follow-up. The phyner with slight unilateral osteoarthritis of the hip had no symptoms, but the two subjects with clearly arthritic hips had definite pain. 


\section{Discussion}

Primary osteoarthritis was found in only $4 \%$ of the athletes, but in $8.7 \%$ of the controls. According to Danielsson $3.4 \%$ of persons over 55 have clear osteoarthritis, ${ }^{1}$ and as many as $30 \%$ in Hermodsson's study. ${ }^{2}$ So competitive sports cannot be considered as a factor that would make osteoarthritis more likely. Nor did any of the runners have changes indicating epiphyseolysis, which Murray and Duncan found in athletes. ${ }^{3}$ Those authors considered that growth disturbances due to stress on the proximal femoral epiphyses, comparable to minimal degrees of epiphysiolysis, were incurred in the early teens.

The aetiology of osteoarthritis remains a mystery, though many theories have been put forward, but our study excludes the possibility that the physical strain to which runner's hips are exposed would contribute to its development. Anatomically and physiologically it is not strange that the hips of competitive runners should be spared osteoarthritis, for the hip is designed for walking and running, ${ }^{4}$ and motion is necessary for the nutrition of the cartilage. By intermittent compression and release, the synovial fluid enters and leaves the cartilage very much in the same way as air enters and leaves the lungs under alternating pressures. On the other hand, both prolonged immobilization and continuous pressure for only six days across the living, cartilage-covered joint surfaces produces ulceration and destruction of the cartilage. ${ }^{5}$ Normally the femoral head can be loaded with up to 15 times body weight before the femoral neck is fractured. ${ }^{4}$ Wolff's law about the adaptation of structure to function may be applied to the hip joint as well as to other tissues of the body. The hip joint is made for movement, and there is no reason to worry about injuries even if it has to sustain a heavy daily load.

1 Danielsson, L., Clinical Orthopaedics, 1966, 45, 67.
2 Hermodsson, I., Acta Radiologica Supplement, 1947, 66, 5.

3 Murray, R. O., and Duncan, C., Fournal of Bone and $\mathcal{F}$ oint Surgery B, 1971, $53,406$.

4 Ryder, N., Clinical Orthopaedics, 1973, 92. 6.

5 Salter, R. B., and Field, P., fournal of Bone and foint Surgery A, 1960, 42,31 .

\begin{tabular}{l} 
University Central Hospital, Oulu, and University Central Hospital, \\
Helsinki, Finland \\
J. PURANEN, M.D., Orthopaedic Surgeon \\
L. ALA-KETOLA, M.D., Radiologist \\
P. PELTOKALIO, M.D., Surgeon \\
J. SAARELA, Running Coach \\
\hline
\end{tabular}

\section{Urinary Retention and Intestinal Obstruction associated with Ano-rectal Herpes simplex Virus Infection}

We describe here two unusual cases of acute urinary retention and intestinal obstruction associated with Herpes simplex virus (H.S.V.) infection of the ano-rectal area.

\section{Case 1}

A 24-year-old male homosexual was first seen in March 1974 with a one-year history of persistent non-specific urethritis, treated elsewhere. At this stage, H.S.V. (untyped) was isolated from his urethra. The H.S. V. complement fixation test (C.F.T.) titre was $<1: 10$. Six months later he complained of anal pain and constipation of several days' duration, inability to rass urine for 24 hours, and severe colicky lower abdominal pain. There were numerous tender ulcers in the ano-rectal area which werenegative for Treponema pallidum. He had practised passive anal intercourse for the first time nine days before. Proctoscopy showed semi-solid faeces and severe proctitis. The bladder was palpable, gut sounds were increased, and a plain radiograph of the was palpable, gut sounds were increased, and a plain radiograph of the abdomen was compatible with large bowel obstruction (fig.). Gram-stained H.S.V. type 2 was isolated (human embryonic lung cells) from both rectal exudate and anal ulcers.

After admission his colicky abdominal pain was relieved by defaecation After admission his colicky abdominal pain was relieved by defaecation
after glycerine suppositories. He later passed urine spontaneously. He was after glycerine suppositories. He later passed urine spontaneously. He was
discharged six days later, while the anal ulcers healed in two weeks. The proctitis persisted for eight weeks, however, throughout which H.S.V. type

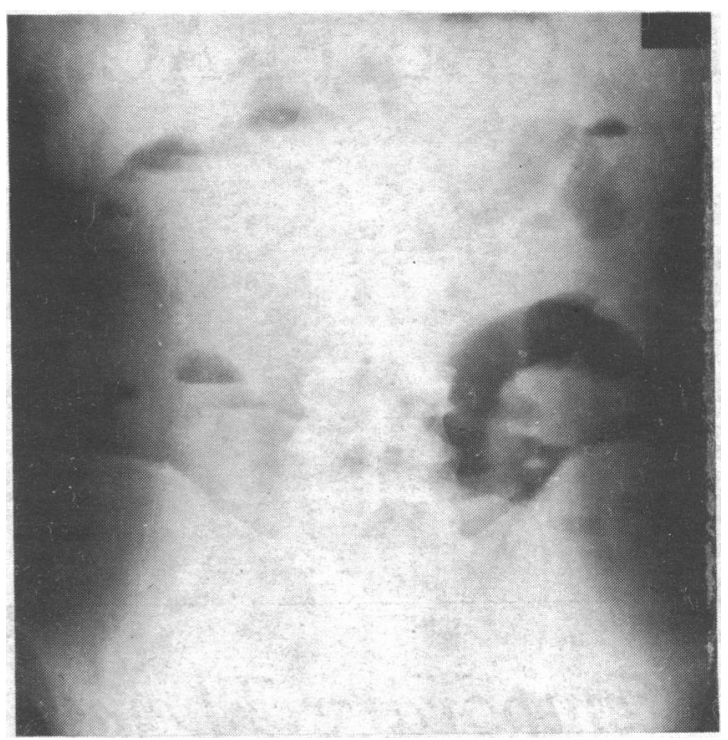

Erect plain radiograph of abdomen showing fluid levels.

2 was repeatedly grown from the rectal exudate, though not afterwards. The H.S.V. C.F.T. titre was still $<1: 10$ on admission, but rose to $1: 320$ eight weeks later. Rectal cultures for the gonococcus and Chlamydia agent, and serological tests for syphilis, were negative.

\section{Case 2}

A 26-year-old male homosexual attended in November 1973 with painful perianal ulceration of a few days' duration. Anal intercourse had taken place 10 days before. The next day he had colicky lower abdominal pain and could not urinate. He had been constipated for seven days. On examination the bladder was palpable to the umbilicus. Numerous tender ulcers were present at the anal margin. These were negative for T. pallidum. Proctoscopy showed a the anal margin. These were negative for $T$. pallidum. Proctoscopy showed a diffuse proctitis and a large amount of semi-solid faeces. Many polymorphs, but no gonococci, were seen in a Gram-stained smear of rectal exudate. He was admitted, and passed $750 \mathrm{ml}$ of urine after a hot bath. He defaecated
after applying $1 \%$ lignocaine to the anal area. The results of cystourethroafter applying $1 \%$ lignocaine to the anal area. The results of cystourethroscopy and urography were normal. On discharge, two weeks later, the proctitis had resolved and bladder function was normal. Swabs taken from the rectal mucosa). Rectal cultures for the gonococcus, and serological tests for syphilis, were negative. The C.F.T. titre for H.S.V. on admission was $1: 20$, and on discharge $1: 40$.

\section{Comment}

Acute urinary retention and constipation may have resulted from reflex spasm of anal and vesical sphincters due to severe anal pain. Both patients had proctitis and in case $1 \mathrm{H.S}$.V. was isolated from the inflamed rectal mucosa. One possibility is that the proctitis resulted from H.S.V. introduced during anal intercourse, with perhaps trauma facilitating viral entry.

Since case 1 had proved urethral H.S.V. infection several months before the ano-rectal involvement, the latter may have resulted in another way. It is thought that between overt attacks of herpetic infection the virus persists in the ganglion cells of the correspondingly infected dermatome, as in sacral ganglia. ${ }^{1}$ A possible mechanism for the ano-rectal lesions in case 1 might, therefore, be a primary urethral infection; persistence of the virus in sacral ganglia; and the trauma of ano-rectal intercourse then reactivating the virus, this leading to herpetic anal ulcers and rectal inflammation.

Cultures for H.S.V. should be taken from all cases of proctitis of uncertain aetiology, especially where anal intercourse is admitted.

Dr. D. Goldmeier was supported by a M.R.C. grant.

1 Baringer, J. R., New England fournal of Medicine, 1974, 291, 828.

Department of Venereology (Whitechapel Clinic), The London Hospital, London E1 1 BB

D. GOLDMEIER, M.B., M.R.C.P., Research Registrar

J. R. M. BATEMAN, B.SC., M.B., Senior House Officer P. RODIN, M.B., M.R.C.P., Consultant Venereologist 